Dossiê Especial: Experiências do PIBID na formação inicial e continuada de professores de

línguas estrangeiras

HIBARINO \& NODARI (orgs)

Revista X, vol.1, 2015

\title{
THANK GOD IT'S FRIDAY: LETRAMENTO CRÍTICO E ENSINO DE INGLÊS EM UMA ESCOLA PÚBLICA
}

Thank God It's Friday: critical literacy and the teaching of English in a public school

\author{
Renata Lilian FOGAÇA ${ }^{1}$ \\ Denise Akemi HIBARINO
}

Resumo: O presente texto tem como propósito relatar o projeto Thank God It's Friday, realizado pelo PIBID - Inglês UFPR durante o ano de $2013 \mathrm{em}$ um colégio público na região de Curitiba. Como fundamentação teórica, este projeto está baseado nas discussões do Letramento Crítico (JORDÃO, 2007; 2013; JORDÃO et al, 2013, MOTTA, 2008) e do Inglês como Língua Internacional (McKAY, 2003; MODIANO; 2001), além das problematizações sobre o ensino/aprendizagem da língua inglesa no contexto brasileiro (LIMA et al, 2011) e das Diretrizes Curriculares de Línguas Estrangeiras (DCELEM, 2008). Como contribuições, esta experiência busca mostrar o processo de elaboração deste projeto, bem como sua implementação e seus desafios na formação do licenciando em Letras.

Palavras-chave: PIBID - UFPR; formação inicial de professores de língua inglesa; Letramento Crítico; Inglês como língua internacional.

\begin{abstract}
The main purpose of this text is to report the project Thank God It's Friday, implemented by PIBID - Inglês UFPR during the year of 2013 in a public school in Curitiba. It is based on the theoretical framework of the Critical Literacy (CL) (JORDÃO, 2007; JORDÃO et al, 2013, MOTTA, 2008) and the discussions of English as an International Language (McKAY, 2003; MODIANO; 2001), in addition to the questioning of teaching/learning English in the Brazilian context and the Curricular Orientations for the teaching of Modern Languages (2008). As its main contributions, this experience aims at eliciting the project elaboration process as well as its implementation and challenges in the development of the Modern Languages undergraduate students.
\end{abstract}

Keywords: PIBID - UFPR; pre-service teacher development; Critical Literacy, English as an International Language.

\section{Introdução}

Este relato pretende compartilhar a experiência do projeto Thank God It's Friday realizado pelo PIBID - Inglês UFPR $^{3}$ no primeiro semestre de 2013 em um colégio da rede pública de Curitiba. Enfatizamos aqui a noção de compartilhar porque entendemos que

\footnotetext{
${ }^{1}$ Bolsista do PIBID-Inglês graduanda do curso de Letras- Inglês UFPR. re.lilian.fog@gmail.com

${ }^{2}$ Doutoranda em Linguística Aplicada pelo IEL/UNICAMP e bolsista CAPES. dhibarino@gmail.com

${ }^{3}$ Thank God It's Friday é uma expressão que significa Graças a Deus é sexta feira utilizada para comemorar o final da semana. No entanto, neste projeto, a expressão também assume um novo sentido: passa a ser usada para valorizar o momento das oficinas de língua inglesa, além das aulas regulares.
} 


\section{Dossiê Especial: Experiências do PIBID na formação inicial e continuada de professores de línguas estrangeiras \\ HIBARINO \& NODARI (orgs) \\ Revista X, vol.1, 2015}

nossas ações foram desenvolvidas como respostas às questões locais, sem a pretensão de torná-las modelos a serem seguidos. Estas ações foram, acima de tudo, o resultado da parceria entre a universidade e a escola pública, negociadas entre os bolsistas, a supervisora e a coordenadora do presente grupo.

Elaborado de forma colaborativa por um grupo de oito bolsistas do curso de Letras, o projeto implementado teve como objetivo geral ministrar oficinas de língua inglesa (doravante LI) aos alunos do ensino fundamental durante as aulas vagas no período da tarde de sexta-feira. Tais aulas foram apontadas pela professora supervisora e co-formadora como um dos maiores problemas de gestão escolar, pois as ausências dos professores por motivos de saúde, ou outro qualquer, tornavam-se momentos ociosos para os alunos que nem sempre podiam ter aulas antecipadas.

Outros objetivos do projeto foram despertar nos alunos, por meio das oficinas, o interesse pela língua inglesa, utilizando uma abordagem contemplasse o Inglês como Língua Internacional (ILI) e as discussões do Letramento Crítico (LC), visada teórica de nosso projeto.

Além disso, no que diz respeito à formação inicial de professores de LI, teve como propósito aproximar os bolsistas do projeto da prática docente por meio dos planejamentos, aplicações de atividades e reflexões sobre as atividades, sempre tentando articulá-los com a fundamentação teórica e vice-versa. E, finalmente, para o professor supervisor, o projeto oportunizou e reforçou seu papel de co-formador neste processor.

Desta maneira, ao invés de reforçar aspectos negativos sobre a escola pública e das dificuldades do ensino da LI, nos apropriamos de várias questões surgidas na leitura do livro Inglês em escolas públicas não funciona?: uma questão, múltiplos olhares de Lima et al (2011) para pensar em alternativas e soluções, ainda que temporárias, como nos ensina o LC, para o problema da escola.

Diante deste exposto, o presente texto apresentará um breve apanhado da fundamentação teórica e, sem seguida, serão descritas as três oficinas realizadas nos dois meses de duração do projeto. Além disso, também serão apresentadas as atividades desenvolvidas e articuladas com os pressupostos teóricos e, posteriormente, a reflexão da bolsista participante.

\section{Fundamentação teórica}


Dossiê Especial: Experiências do PIBID na formação inicial e continuada de professores de

línguas estrangeiras

HIBARINO \& NODARI (orgs)

Revista X, vol.1, 2015

Nosso projeto foi orientado inicialmente pela leitura do projeto pedagógico do colégio no qual estávamos atuando e de documentos oficiais como as Diretrizes Curriculares para o Ensino de Língua Estrangeira Moderna (DCE-LEM, 2008), que norteia o ensino na rede pública do Paraná. Do primeiro, pudemos entender como está organizada a estrutura e funcionamento do colégio, bem como o perfil dos alunos, aspecto importante para a escolha de temas de nossa oficina e compreensão do contexto sócio-educacional.

Já com relação ao segundo, discutimos a relevância de desenvolver práticas de linguagem significativas para o aluno, pois é por meio delas que conseguimos despertar seu interesse e o pensamento crítico. Outro ponto marcante desta leitura foi a concepção discursiva de língua, também presente nos pressupostos do Letramento Crítico (LC) (EDMUNDO, 2010; JORDÃO, 2007; JORDÃO et al, 2013) que, para muitos do nosso grupo de bolsistas, constituiu-se como uma perspectiva nova e desafiadora uma vez que nos fez repensar sobre nossos papeis enquanto alunos, bolsistas e futuros professores de LI, desconstruir e resignificar o espaço da escola e pensar na importância da LI neste contexto.

Ao considerar língua enquanto discurso, passamos a não mais entendê-la como um simples código para a transmissão e captação de mensagens. Ela passa a ser entendida, então, como espaço de construção de sentidos ${ }^{4}$ (JORDÃO, 2007; JORDÃO et al, 2013). Assim sendo, ao ensinar e aprender línguas, atribuímos e produzimos sentidos, “(...) sempre parciais e incompletos, porque localizados ${ }^{5}$, ideologicamente marcados e sempre passíveis de mudança" (JORDÃO, 2007, p.21). Este entendimento teve impacto significativo em nossas práticas em sala de aula, pois nos fez sair de uma visão estruturalista de ensino (código), aquela pelo qual havíamos estudado enquanto alunos, para considerar que:

(...) além das condições de produção de um texto escrito ou oral, verbal ou visual, é preciso também pensar sobre os contextos em que a própria leitura se realiza, ou seja, as condições para atribuição e construção de sentidos que se confere a um texto ou a uma unidade de sentido. É fundamental no LC pensar e falar também sobre o entorno social, político, cultural e ideológico das circunstâncias da leitura, sobre as comunidades interpretativas legitimadas e não legitimadas, sobre as formas privilegiadas e nãoprivilegiadas de ler e assim atribuir, hierarquizar e construir sentidos. (JORDÃO et al, 2013, p. 42).

Portanto, o uso da língua inglesa na escola é uma “(...) oportunidade de resignificar sentidos, representações, procedimentos, valores, ou menos, atribuir novos sentidos ao

\footnotetext{
${ }^{4}$ Grifo das autoras

${ }^{5}$ Grifo da autora
} 
Dossiê Especial: Experiências do PIBID na formação inicial e continuada de professores de línguas estrangeiras

HIBARINO \& NODARI (orgs)

Revista X, vol.1, 2015

mundo" (JORDÃO et al, 2013, p. 43), principalmente se levarmos em consideração as discussões do ILI que também nos orientaram neste projeto. As leituras de autores como Modiano (2001) e McKay (2003) contribuíram para que, enquanto professores em formação inicial, refletíssemos de que forma o ILI tem alterado nossas formas e aprender e ensinar esta língua. Uma das contribuições principais foi contestar a ideia de que nossos alunos precisariam atingir um nível de proficiência similar ao de um falante nativo idealizado, mito ainda muito presente em nossa sociedade. Ao desconstruir este mito, partilhamos da ideia de McKay (idem) de que é inconcebível pensar que alguns falantes de inglês sejam mais privilegiados do que os outros e que devam ser considerados padrões a serem seguidos.

Para Modiano (idem), impor uma única variedade ou um padrão significa doutrinar o aprendiz, ao invés de mostrar as diferentes variedades do inglês no mundo globalizado, principalmente aquelas produzidas pelos falantes não-nativos. Deste modo, valorizar o inglês produzido e conhecido por nossos alunos passou a ser também objetivo do projeto.

Em linhas gerais, foram estas as concepções gerais que nortearam o desenvolvimento deste projeto e serão explicitadas a seguir.

\section{Planejamento das atividades e organização do trabalho}

Conforme mencionado anteriormente, o projeto acontecia sempre às sextas-feiras de forma alternada: em uma sexta, os oito bolsistas e a supervisora planejavam a oficina, sempre tendo em mente que as atividades deveriam ser flexíveis para serem aplicadas em turmas de $6^{\circ}-9^{\circ}$ ano uma vez que não tínhamos previsão de quais turmas estariam com aulas vagas. $\mathrm{Na}$ sexta-feira seguinte, uma dupla era responsável pelo encaminhamento das atividades, enquanto os demais monitoravam. Depois de cada oficina, havia feedback por parte da supervisora, reflexões do grupo sobre o que havia dado certo e o que poderia ser melhorado e a definição da próxima dupla responsável pelo planejamento da oficina.

É importante lembrar que não podíamos montar uma proposta a ser desenvolvida ao longo de um determinado período pelo fato de não termos uma turma fixa. Mesmo assim, nos preocupávamos em estabelecer certa conexão com a atividade aplicada anteriormente por uma questão de organização. Quando não havia professor faltando e, por conseguinte, não teríamos alunos para atender, o grupo usava o tempo na escola para discutir o planejamento de outras atividades e tentando articular os pressupostos teóricos do LC com a prática em sala de aula. 


\section{Dossiê Especial: Experiências do PIBID na formação inicial e continuada de professores de línguas estrangeiras \\ HIBARINO \& NODARI (orgs) \\ Revista X, vol.1, 2015}

\section{Em ação}

Nesta sessão apresentamos e descrevemos três oficinas realizadas durante os dois meses de duração do projeto. A apresentação se dará pela menção do título da ofícina e pelo detalhamento acerca da aplicação das atividades.

\section{Oficina 1- Crazy Society}

Essa foi a primeira oficina trabalhada em um dia em que o quadro de professores estava completo. Contudo, para que pudéssemos dar inicio ao projeto, a professora supervisora conversou com um professor que concordou em ceder a sua aula para que os alunos pudessem participar da oficina.

Escolhemos a música $\mathrm{Crazy}^{6}$ da banda Simple Plan não só por ser conhecida dos alunos mas por trazer críticas no que diz respeito às formas como o culto ao corpo, as relações familiares e as diferenças sociais são representadas pela mídia. Primeiramente, contextualizamos o título e explicamos que os alunos deveriam escutar a música e colocar as estrofes que a compunham em ordem na folha de exercícios (anexo 1). Depois de trabalhar a compreensão oral, cada bolsista se responsabilizou por um grupo e mediou uma discussão sobre algumas das críticas citadas na música.

Nesta mediação, trabalhamos em português e incentivamos os alunos a construírem sentidos a partir do que haviam entendido. Como muitas das palavras eram conhecidas dos alunos (money, photoshoped pictures, money, kids), alguns tiveram facilidade para entender e, com base em seus entendimentos de mundo, construíram suas opiniões sobre o poder da mídia, responsável por perpetuar padrões e estereótipos a serem seguidos e, perceberam que, na verdade, poderiam ser eles mesmos que reproduziam tais crenças e estereótipos sem pensar criticamente.

Após essa discussão, cada grupo de alunos selecionou um trecho da música com o qual tivesse se identificado e criou um desenho ou uma produção escrita expressando o que pensaram sobre a crítica escolhida.

A realização desta atividade nos ajudou a entender como os alunos, a partir das críticas presentes na música, constroem sentidos e resignificam valores a partir de suas vivências ao trazer suas diferentes visões de mundo para a discussão em grupo. Essas diferentes visões

\footnotetext{
${ }^{6}$ Disponível em: 〈http://www.vagalume.com.br/simple-plan/crazy-traducao.html >
} 
Dossiê Especial: Experiências do PIBID na formação inicial e continuada de professores de línguas estrangeiras

HIBARINO \& NODARI (orgs)

Revista X, vol.1, 2015

foram produtivas para as discussões, principalmente para que eles se percebessem enquanto sujeitos críticos em uma prática significativa, conforme orientam as DCEs-LEM (2008).

\section{Oficina 2 - Dove: Retratos da Real beleza}

A intenção da oficina era trazer à tona novamente questões sociais como ideais impostas pela mídia como havíamos feito anteriormente. Para isso, utilizamos o vídeo Retratos da Real Beleza da Dove ${ }^{7}$,marca de sabonete conhecida por desenvolver campanhas que descontroem o padrão de beleza imposto em nossa sociedade. Constituído por depoimentos de mulheres e suas auto-descrições físicas, o vídeo mostra como suas belezas podem ser percebidas e reconstruídas pelo olhar de um artista que, sem nenhum tipo de contato anterior, as retrata em um esboço preto e branco. Ao se verem retratadas pelo olhar do outro, se surpreendem ao perceber detalhes até então invisíveis sobre si, por exemplo, sua beleza natural, desvinculada de detalhes como cicatrizes e marcas de velhice.

Apesar de ser todo em inglês, os alunos participaram ativamente e compreenderam a ideia central do vídeo. Em seguida, formaram duplas e fizeram um retrato do colega (figura 3) que estava à frente, assim como no vídeo.

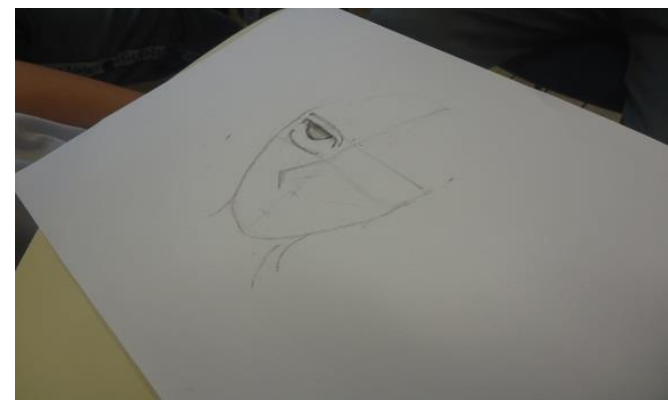

Figura 3

Como forma de incentivar o uso do vocabulário visto no vídeo, eles escreveram adjetivos em inglês que ajudassem a descrever o colega, com ajuda de dicionário e dos bolsistas que escreveram as palavras no quadro. Ao compararem o que eles tinham em mente sobre si mesmos com o retrato produzido, tiveram reações de surpresa, como as personagens do vídeo.

Esta atividade trabalha com o impacto que o olhar do outro tem sobre nós mesmos e como pequenos detalhes levam à baixa auto-estima, principalmente na fase da adolescência

\footnotetext{
${ }^{7}$ Disponível em: https://www.youtube.com/watch?v=I10nz0LHbcM\&feature=share.
} 
Dossiê Especial: Experiências do PIBID na formação inicial e continuada de professores de línguas estrangeiras

HIBARINO \& NODARI (orgs)

Revista X, vol.1, 2015

quando a prática do bullying tem consequências negativas. Desta forma, trazer para a sala de aula temas como este e promover a atividade do retrato oportunizaram uma forma de repensar como nos vemos e como o olhar do outro nos constrói. Mais importante ainda foi resignificar uma atividade que poderia ser somente de apresentação de vocabulário de descrição física para problematizar padrões de beleza presentes na sociedade brasileira.

\section{Oficina 3- Teenage Problems}

Essa atividade foi preparada visando discutir com os alunos as situações-problemas que eles possivelmente enfrentam durante a adolescência. Ao iniciar a aula, esperamos as reações dos alunos ao chamá-los de kids (crianças) e discutimos o que faz de alguém criança, adolescente e adulto. Depois dessa discussão, os alunos receberam cartões do Tumblr ${ }^{8}$ (anexo 2) nos quais estavam escritos (em inglês) problemas típicos da adolescência em frases curtas ou gírias sobre distúrbios alimentares, permissão aos para sair, problemas na escola, pressão para ser bom em tudo, etc. Cada bolsista mediou um debate com um grupo de alunos que deveriam expressar suas opiniões sobre os problemas apresentados e tentar estabelecer ligações entre os problemas citados e a realidade deles. Após essa discussão, eles montaram um cartaz com o título What do teenagers want? ${ }^{9}$ no qual deveriam colar ou desenhar figuras que expressassem suas ambições naquela fase. Nas produções abaixo, podemos perceber as prioridades de cada grupo: liberdade, dinheiro, namorado, etc. Em cada uma delas, cada palavra utilizada tinha sentidos diferentes. Por exemplo, a liberdade na figura (1) abaixo (freedom) era não só a liberdade de pensamento, mas também a liberdade de se vestir da forma que quisessem, de sair com os amigos quando e como quisessem. Já o termo namorado (boyfriend) também causou conversas interessantes no que diz respeito ao gênero: enquanto as meninas argumentavam que gostariam de ter um namorado, um dos meninos do grupo sugeriu que algumas meninas gostam de meninas também. Assim, as palavras boyfriend/girlfriend (namorado e namorada) deveriam estar juntas no mesmo balão.

\footnotetext{
${ }^{8}$ Disponível em: http://teenage-problems.tumblr.com/

${ }^{9}$ What do teenagers want? Significa "O que os adolescentes querem?" em Português.
} 
Dossiê Especial: Experiências do PIBID na formação inicial e continuada de professores de línguas estrangeiras

HIBARINO \& NODARI (orgs)

Revista X, vol.1, 2015

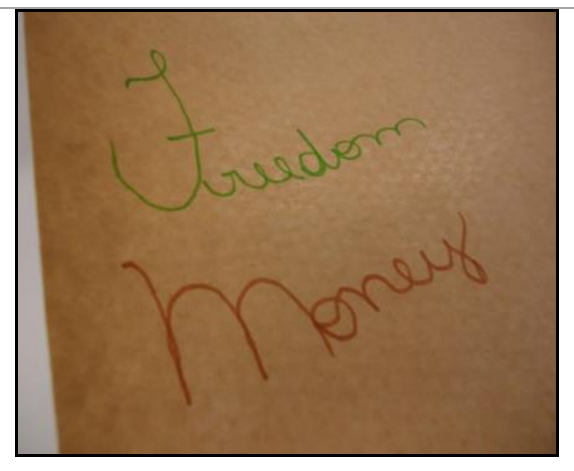

Figura 1

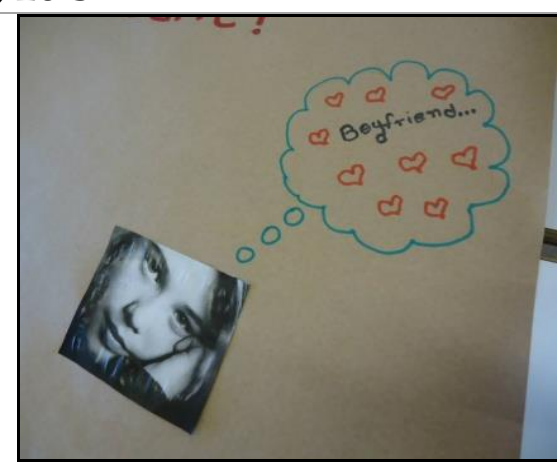

Figura 2

De forma geral, eles corresponderam as nossas expectativas: não quiseram ser chamados de crianças e colocaram outros problemas específicos, por exemplo, odiavam a escola, demonstravam não ter apego aos pais, eram criticados por seu estilo de roupa e preferência sexual. Assim, compreender os anseios dos alunos, como se sentem e por que se sentem de tal maneira foi interessante, pois nos deparamos com realidades um tanto duras com relação ao dia a dia daqueles adolescentes.

O contato com os problemas postados por outros adolescentes de outros países no Tumblr oportunizou não só a identificação, mas, por outro lado, diferentes entendimentos de um mesmo problema. Em uma das situações, ao lerem o problema "teachers who hate you", os alunos puderam pensar na relação entre professor e aluno, nos motivos que levam um aluno a pensar que o professor não gosta dele e vice-versa e qual o impacto desta relação durante as aulas. Não raro, os alunos mencionaram quais professores eram legais e o que fazia uma aula ser boa. Assim sendo, discutir sobre estes problemas instigou os alunos a pensarem de forma crítica sobre seu papel em sala de aula.

\section{Considerações finais}

Trabalhar a partir da perspectiva do LC foi muito significativa para mim enquanto bolsista. Houve erros e acertos com relação à escolha de atividades, tempo de preparo, uso de tecnologia, entre outros, mas nossas atividades tiveram como objetivo não só desenvolver as práticas de leitura, escrita, oralidade e compreensão oral, mas, acima de tudo, como aponta Motta (2008), partimos “(...) do o texto, oral, escrito ou visual como uma oportunidade para uma reflexão crítica. (p.13)” de temas como os padrões de beleza impostos pela mídia, as relações em família e o consumo presente em nossa sociedade conforme trabalhamos nas três oficinas. 


\section{Dossiê Especial: Experiências do PIBID na formação inicial e continuada de professores de línguas estrangeiras \\ HIBARINO \& NODARI (orgs) \\ Revista X, vol.1, 2015}

De acordo com o que foi relatado, conclui-se que a experiência como bolsista traz uma experiência extremamente válida sobre o que é ser professor em um colégio da rede pública, como lidar com as adversidades (problemas técnicos, problemas com comportamento e a falta da participação de alguns alunos) e, principalmente, ao colocar em prática a teoria lida e discutida previamente. Ao pensar em temas e atividades que fossem coerentes com a proposta teórica, nosso grupo questionava-se frequentemente se havia entendido o conceito de LC, se a atividade estava voltada para o conceito de língua enquanto código e não língua enquanto discurso ou vice-versa, se e como nossos alunos estavam construindo sentidos e desenvolvendo sua criticidade. Este exercício de nos percebermos enquanto construímos sentidos, dentro e fora da sala de aula como estão registrados em nosso diário de bordo ${ }^{10}$, traduz o movimento de "ler, se lendo", apontado por Menezes de Souza (2011).

Outro aspecto relevante desta experiência foi desconstruir a noção de "ter aula". Em uma visão mais tradicionalista, uma aula que só tem discussão não é aula e, como o desenvolvimento do olhar/pensamento crítico não é tão palpável e "instantâneo" quanto o registro no caderno, muitos pais e alunos têm dificuldade em perceber que uma discussão em sala de aula pode ser mais rica do que as anotações de um caderno tendo, inclusive, repercussões a longo prazo.

Ademais, ao assumir a posição como bolsista, tinha consciência que me depararia com uma realidade escolar diferente da universidade, com a multiplicidade de sentidos que seriam produzidos no espaço da sala de aula e como teria que negociá-los, sem impor uma única verdade ou verdades como se fossem absolutas. Desta forma, o projeto buscou “(...) contrapor o conhecido ao desconhecido, e sempre neste processo respeitar nossas diferentes vozes e os diferentes lugares ocupados por cada um (...)”(JORDÃO, 2013, p. 25).

Tenho consciência, no entanto, que o tempo e espaço de dois meses talvez tenha sido limitado para aprofundar questões linguísticas. Todavia, o propósito não era, segundo a fundamentação teórica, atingir um nível avançado de LI, tampouco a idealização de um falante nativo. Dentro da abordagem do LC, foi possível trabalhar com as questões sociais, políticas e culturais presentes na realidade dos alunos e fazê-los se perceberem enquanto sujeitos críticos e produtores de sentidos, como a oficina Crazy Society demonstrou.

Finalmente, esta experiência compartilhada representa o que Gimenez (2009) defende sobre os programas de formação de professores: trazem mudanças na dinâmica da escola,

\footnotetext{
${ }^{10}$ Grupo fechado do GoogleSites.
} 
Dossiê Especial: Experiências do PIBID na formação inicial e continuada de professores de línguas estrangeiras

HIBARINO \& NODARI (orgs)

Revista X, vol.1, 2015

possibilitam projetos que atendem necessidades locais e, principalmente, envolvem professores em formação inicial e continuada.

\section{Agradecimento}

Agradecemos à CAPES pela concessão das bolsas (doutorado e PIBID) que possibilitaram a realização desta pesquisa.

\section{Referências}

GIMENEZ, T.N. "Ensinar a aprender ou ensinar o que aprendeu?" IN: LIMA, D. C. (org). Ensino de aprendizagem de língua inglesa: conversas com especialistas. São Paulo: Parábola Editorial, 2009, Pp.107-112.

JORDÃO, C. M. As lentes do discurso: letramento e criticidade no mundo digital. Trabalhos em Linguística Aplicada,v.1, n.46,p. 19-29, Jan./Jun.2007.

"Letramento crítico, inglês como língua internacional e ensino: as marés do PIBID-Inglês da UFPR". IN: MATEUS; E. et al. Experiências de formação de professores de línguas e o PIBID: contornos, cores e matizes. Campinas, SP: Pontes Editores, 2013, Pp.21-47.

JORDÃO, C.M et al. O PIBID nas aulas de Inglês: divisor de águas e formador de marés. Campinas, SP: Pontes Editores, 2013.

LIMA, D. C. (org). Inglês em escola pública não funciona? Uma questão, múltiplos olhares. São Paulo: Parábola Editorial, 2011.

MOTTA, A.P.F. $O$ ensino/ aprendizagem de língua inglesa sob a perspectiva docente. 2008. Disponível em <http://www.diaadiaeducacao.pr.gov.br/portals/pde/arquivos/379-4.pdf> (acesso em 05/04/2014).

PARANÁ. Secretaria de Estado da Educação. Diretrizes Curriculares da Educação Básica. Língua Estrangeira Moderna. Curitiba: SEED, 2008. 
Dossiê Especial: Experiências do PIBID na formação inicial e continuada de professores de línguas estrangeiras

HIBARINO \& NODARI (orgs)

Revista X, vol.1, 2015

ANEXOS

ANEXO 1

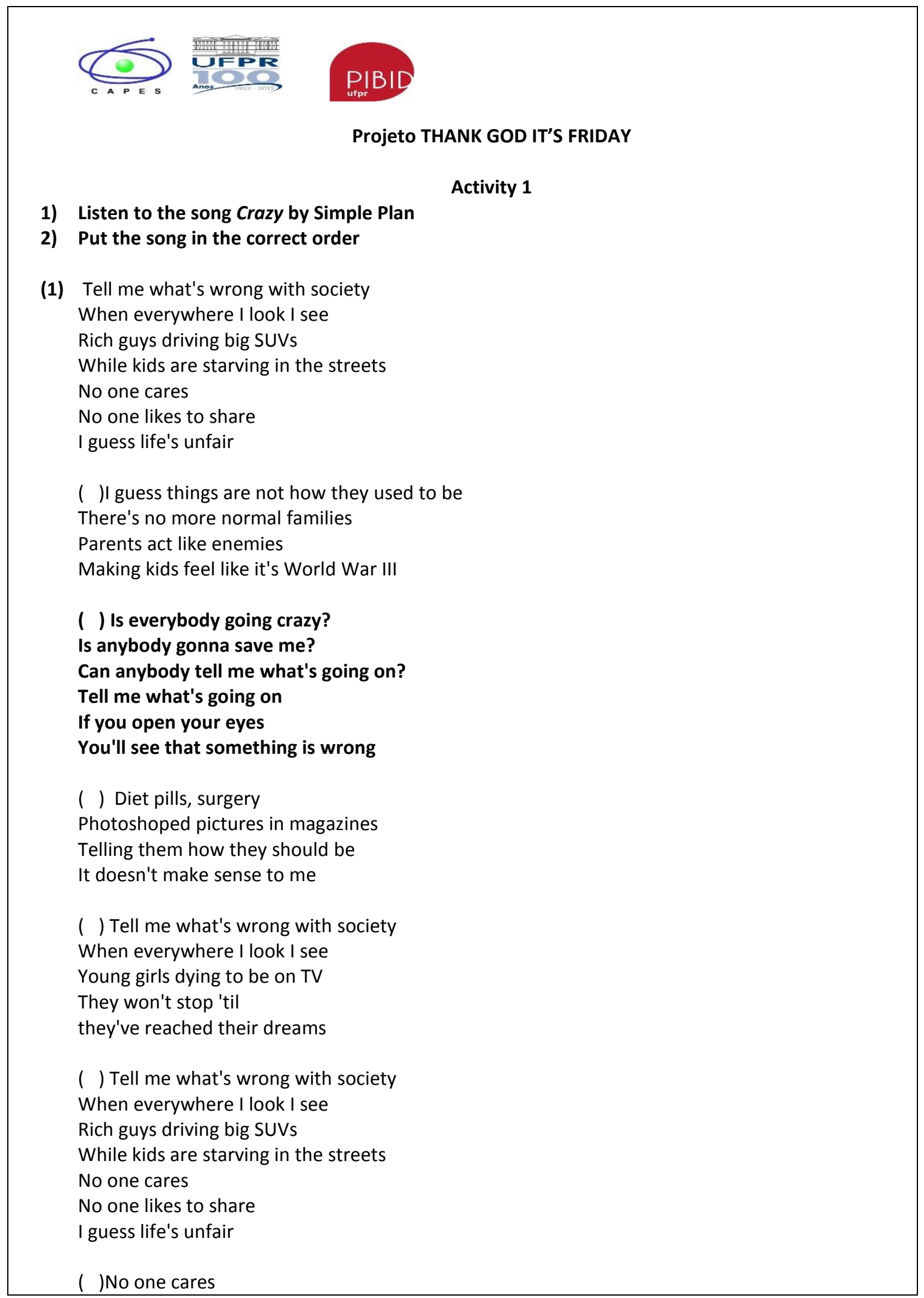


Dossiê Especial: Experiências do PIBID na formação inicial e continuada de professores de línguas estrangeiras

HIBARINO \& NODARI (orgs)

Revista X, vol.1, 2015

\author{
No one's there \\ I guess we're all just too damn busy \\ Money's our first priority \\ It doesn't make sense to me \\ ( ) Is everybody going crazy? \\ Is everybody going crazy?
}

Adaptado do site: 〈http://www.vagalume.com.br/simple-plan/crazy-traducao.html〉 
Dossiê Especial: Experiências do PIBID na formação inicial e continuada de professores de línguas estrangeiras

HIBARINO \& NODARI (orgs)

Revista X, vol.1, 2015

ANEXO 2

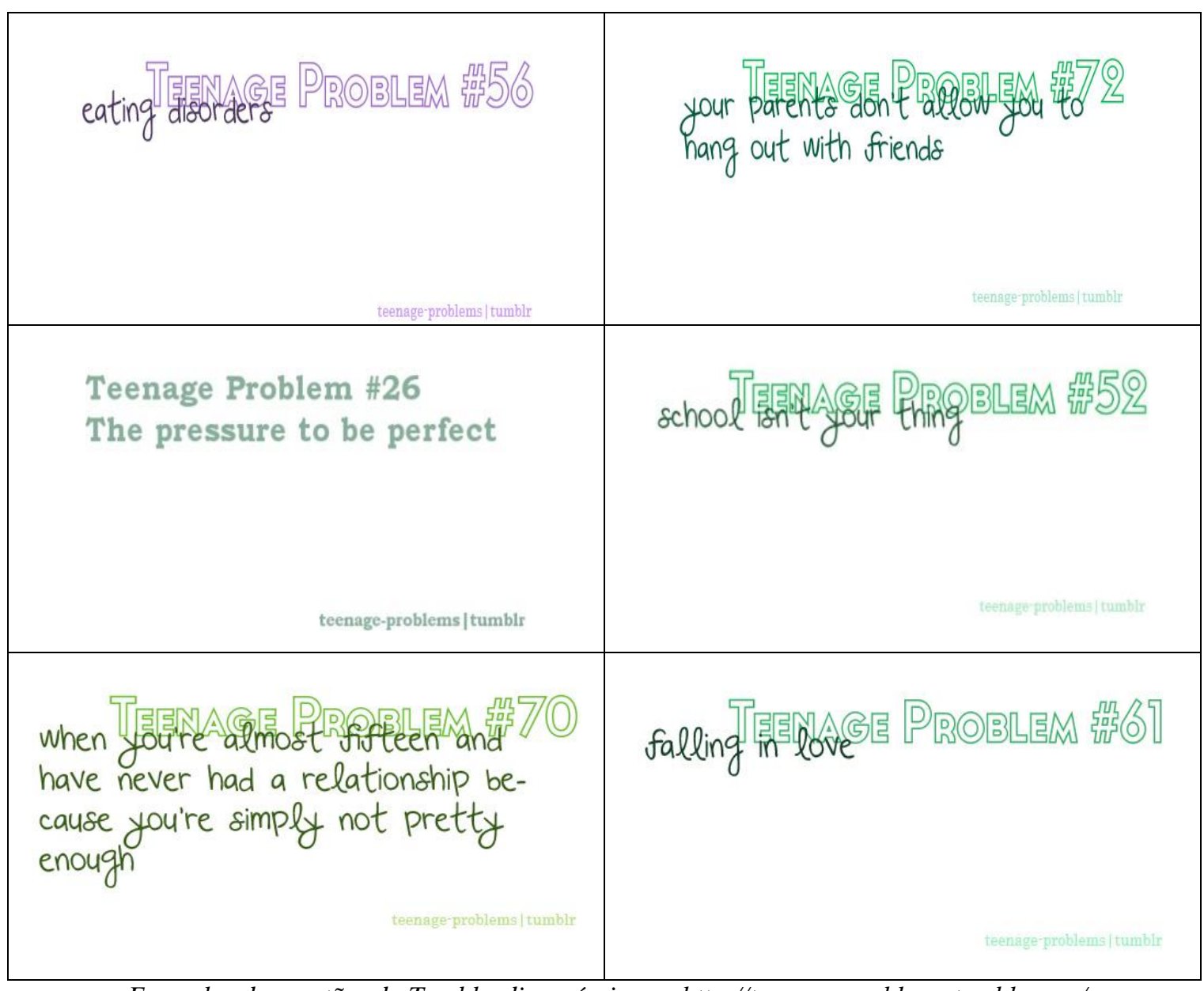

Exemplos dos cartões do Tumblr, disponíveis em: http://teenage-problems.tumblr.com/ 